\title{
Desenvolvimento da argumentação em uma sequência de ensino investigativa sobre termoelétrica
}

\section{Development of the argumentation in an Inquiry-Based Teaching}

Sequence about thermoelectricity

\author{
Filipe Silva de Oliveira, Maria Clara Pinto Cruz e Adjane da Costa Tourinho e Silva
}

Resumo: $\mathrm{O}$ artigo discute uma situação argumentativa instaurada na segunda fase de uma Sequência de Ensino Investigativa (SEI), cuja estrutura inspira-se na proposta de Pedaste et al. (2015). O objetivo da SEI foi promover a compreensão de conteúdos da Química e da Física, tendo em vista o funcionamento de uma usina termoelétrica, aliando aspectos científicos a socioambientais. As argumentações desenvolvidas em torno de um experimento envolvendo a geração de energia elétrica a partir de energia térmica foram analisadas e discutidas por meio do Modelo de Argumento de Toulmin. Notou-se o investimento do professor na percepção dos alunos acerca dos conhecimentos interdisciplinares teóricos a fim de que elaborassem sentido para os dados experimentais e construíssem seus argumentos. Verificou-se, ainda, a construção de argumentos mais completos com dados, conclusões e garantia de inferência. Estes argumentos discutidos em grupo e individualmente junto ao professor expressaram um avanço conceitual.

Palavras chave: sequência de ensino investigativa, argumentação, química, física.

\begin{abstract}
The paper discusses an argumentative situation that began in the conceptualization phase of an Inquiry-Based Teaching Sequence, whose structure is inspired by the proposal of Pedaste et al. (2015). The objective of the SEI was to promote the understanding of Chemistry and Physics contents, in view of the operation of a thermoelectric plant, combining scientific and social-environmental aspects. Arguments developed around an experiment involving the generation of electrical energy from thermal energy were analyzed and discussed using Toulmin's Argument Model. It is noted the teacher's investment in the students' perception of the theoretical interdisciplinary knowledge for purposes of elaboration of meaning for experimental data and arguments building. There was also a construction of more complete arguments with data, conclusions and guarantee of inference. These arguments discussed in the group and with the teacher expressed a conceptual advance.
\end{abstract}

Keywords: inquiry-based teaching sequences, argumentation, chemistry, physics

\footnotetext{
Filipe Silva de Oliveira (oliveiradefs@ gmail.com), licenciado em Química pela Faculdade Pio Décimo, mestre em Ensino de Ciências em Matemática pela Universidade Federal de Sergipe. Aracaju, SE - BR. Maria Clara Pinto Cruz (clara_aju@ yahoo.com.br), graduada em Química Industrial pela Universidade Federal de Sergipe, licenciada em Química pela Faculdade Pio Décimo, mestra em Química e doutora em Engenharia Química, ambos pela Unicamp. Atualmente é professora no curso de Licenciatura em Química da Faculdade Pio Décimo e professora do Estado de Alagoas em Penedo. Aracaju, SE - BR. Adjane da Costa Tourinho e Silva (adtourinho@terra.com.br), licenciada em Química pela Universidade Federal de Sergipe, mestra em Educação pela Universidade Federal de Sergipe e doutora em Educação pela Universidade Federal de Minas Gerais. Atualmente é professora do Núcleo de Pós-Graduação em Ensino de Ciências e Matemática -NPGECIMA- Universidade Federal de Sergipe. Aracaju, SE - BR.
}

Recebido em 05/05/2019, aceito em 20/10/2019

A seção "Cadernos de Pesquisa" é um espaço dedicado exclusivamente para artigos inéditos (empíricos, de revisão ou teóricos) que apresentem profundidade teórico-metodológica, gerem conhecimentos novos para a área e contribuições para o avanço da pesquisa em Ensino de Química. 
No Brasil, tem-se notado um aumento de pesquisas na área de Ensino de Ciências envolvendo a produção de Sequências de Ensino Investigativas (SEI) (Moraes e Carvalho, 2018; Ferraz e Sasseron, 2017 Scarpa e Campos, 2018). Consistindo em um conjunto de aulas planejadas de modo a possibilitar que as investigações aconteçam em sala de aula, as SEI envolvem uma série de atividades ordenadas, estruturadas e articuladas em prol da resolução de um problema de natureza científica ou sociocientífica, que se expressa por meio de uma ou mais questões. Nesse sentido, as relações entre dados experimentais, ou oriundos de observações sistemáticas, com conhecimentos teóricos, voltadas à elaboração de respostas às questões propostas, abrem espaço para a argumentação.

$\mathrm{O}$ caráter investigativo de uma sequência de ensino evidencia-se em suas etapas. O termo investigação geralmente presume o processo de planejamento e desenvolvimento de estratégias em função de uma questão em pauta (Sandoval, 2005). Produzir, analisar e interpretar dados, elaborar conclusões a partir deles e comunicar tais conclusões a uma audiência, a fim de legitimá-las por meio de um discurso argumentativo, emergem como práticas epistêmicas características de atividades investigativas (Kelly, 2005). Carmo e Carvalho (2014), por exemplo, enfatizam os seguintes aspectos no desenvolvimento de uma SEI: a relevância de um problema para início da construção do conhecimento; a passagem da ação manipulativa à ação intelectual; a importância da tomada de consciência dos próprios atos ao longo do processo; e as diferentes etapas das explicações elaboradas em torno do fenômeno investigado.

Sequências de ensino investigativas devem proporcionar aos alunos a construção de conceitos ao longo de seu engajamento em práticas epistêmicas que lhes permitam compreender aspectos inerentes ao trabalho de investigação científica. Kelly $(2008,2016)$ define práticas epistêmicas como formas socialmente organizadas e interativamente realizadas por meio das quais membros de um grupo propõem, comunicam, avaliam e legitimam asserções do conhecimento. Nessa perspectiva, a argumentação emerge como uma prática epistêmica relevante, a qual permeia todo o processo de investigação, tanto na ciência real, quanto na ciência escolar.

Elaborar uma sequência de ensino de caráter investigativo presume atentar para como as suas diferentes etapas se entrelaçam de modo a promover um conjunto coerente de ações que favoreçam a articulação entre perguntas e repostas. Neste sentido, busca-se proporcionar a construção de conhecimentos, ao tempo em que os alunos vivenciam aspectos fundamentais que ancoram as investigações científicas reais.

Neste artigo, tratamos de uma SEI intitulada "Termoquímica: energia, termoelétrica e sociedade", considerando o processo argumentativo instaurado em uma de suas etapas fundamentais. A SEI foi estruturada com base na proposta de Pedaste et al. (2015), tendo em vista os pressupostos da alfabetização científica, por meio da contextualização crítica para tomada de decisões, como defendida por Santos (2007). O tema surgiu em função da implantação de uma usina termoelétrica na cidade vizinha (Barra dos Coqueiros) àquela em que a SEI foi desenvolvida, a cidade de Aracaju, em Sergipe.

A alfabetização científica pode ser entendida como um processo em que o indivíduo interage com uma nova cultura a científica - a qual lhe proporciona a percepção de uma nova forma de ver o mundo e seus acontecimentos. Representa, portanto, a apropriação de elementos que se constituem em uma ferramenta a mais a ser utilizada na interação com o ambiente ao seu redor. Além disso, possibilita-lhe modificar tal ambiente e a si próprio, tendo em vista os saberes científicos adquiridos e as habilidades associadas ao fazer científico (Sasseron, 2008).

Neste contexto, foram consideradas, no desenvolvimento da SEI, as disciplinas Química e Física. Aliar duas disciplinas notadamente complexas para os alunos é um desafio ainda pouco explorado na prática. Para tal, a intervenção do professor na condução dos alunos aos conceitos dessas duas disciplinas, de modo a favorecer a compreensão do funcionamento de uma termoelétrica, requer atenção, uma vez que os alunos sentem dificuldades em interligar conceitos envolvidos nestes ramos do conhecimento.

Vale ressaltar que, embora aspectos sociais e ambientais tenham sido abordados nas etapas inicial e final da SEI, a discussão que apresentamos neste artigo considera especificamente a argumentação de natureza científica desenvolvida na fase de conceitualização/investigação da sequência (Pedaste et al., 2015), em que questões e hipóteses foram articuladas em torno de um experimento desenvolvido a fim de introduzir conceitos fundamentais para o entendimento do funcionamento de uma termoelétrica.

A abordagem pedagógica se insere na linha sociointeracionista, com a valorização das concepções prévias dos estudantes e do processo de internalização de ideias em sala de aula. Ela parte da premissa vygotskiana da linguagem e outros recursos semióticos como meio relacional entre o sujeito e o mundo, resultando na construção de novos significados. Nesta tradição, a linguagem humana e os processos interativos em sala de aula passam a ser valorizados (Lemke, 1990; Scott, 1998; Mortimer,1998; Mortimer e Machado, 2000; Kelly, 2011).

Para Vygotsky (1993), o desenvolvimento cognitivo consiste na conversão de relações sociais em funções mentais. Portanto, nesta perspectiva, investir na argumentação e em outras práticas discursivas é, fundamentalmente, favorecer a mobilização social de ideias e sua apropriação pelos alunos. Como discute van Manen (1990, apud NASCIMENTO; VIEIRA, 2009), a construção de argumentos pode tornar o pensamento dos alunos mais visível, representando uma ferramenta de avaliação e auto avaliação, favorecendo, assim, o processo de metacognição.

Portanto, o objetivo deste artigo é apresentar uma análise da elaboração de argumentos pelos alunos em diálogo com o professor e em respostas escritas a questões propostas na segunda fase da SEI - a fase de conceitualização/investigação. 
A análise foi desenvolvida por meio do Padrão de Argumento de Toulmin (2006). Considerando situações de produção conjunta de argumentos pelos alunos entre si e com a mediação do professor, verificamos como os elementos deste modelo apareciam, gradativamente, ao longo das interações.

\section{Aspectos Teórico-metodológicos}

\section{O Padrão de Argumento de Toulmin (Toulmin's Pattern Argument - TAP)}

Segundo Toulmin (2006), quando fazemos nossas alegações e somos desafiados a prová-las, recorremos a alguns fatos, os quais irão nos valer para apoiar essas alegações. Com isso, o autor diferencia o que é considerado como conclusão (C), ou seja, a alegação cujos méritos procuramos estabelecer, dos fatos aos quais buscamos para fundamentar tal alegação (D). A partir daí, expande-se a ideia de argumento de estrutura "se D, então C", acrescentando-se as garantias de inferência (W) que a alegação requer. São tais garantias que permitem a passagem dos dados à conclusão. Elas são o elemento que possibilita que a conclusão seja inferida a partir dos dados iniciais. A estrutura básica de um argumento é, portanto: "a partir de um dado D, já que W, então C".

A essa estrutura básica, podem ser acrescentados: qualificadores modais (Q), que especificam as condições necessárias para que a garantia de inferência seja válida, indicando uma referência explícita ao grau de força que os dados conferem à conclusão; refutações (R), que especificam em que condições a garantia não é válida, e apoio ou conhecimento de base (B), elemento que dá suporte à garantia de inferência.

Qualificadores modais (Q), refutadores (R) e apoio ou conhecimento de base (B) são, portanto, elementos que ampliam a estrutura básica de argumento proposta por Toulmin, evidenciando argumentos mais elaborados estruturalmente que aqueles compostos apenas por dado (D), conclusão (C) e garantia de inferência (W). Os qualificadores consistem em palavras ou frases que expressam o nível de certeza dos falantes a respeito da alegação que desejam sustentar. Nesse sentido, é comum que, compondo os qualificadores, apareçam palavras tais como: certamente, provavelmente ou possivelmente, as quais se colocam antes da conclusão apresentada. Os refutadores, por sua vez, especificam em que condições a garantia não é suficiente para dar suporte à conclusão. Assim, uma determinada conclusão é legitima em função de certas condições consideradas, mas passa a se tornar questionável se tais condições mudam. Isso é expresso nos refutadores. Os conhecimentos de base, por fim, correspondem a ideias amplas ou gerais que sustentam as garantias de inferência, as quais estão mais especificamente ou diretamente associadas aos dados e à conclusão. Trata-se de conhecimentos mais categóricos, como um princípio, uma lei, teoria ou fato histórico consagrado na literatura. Dados, garantias de inferência e conhecimentos de base podem ser considerados elementos justificatórios, aos quais os locutores recorrem para ancorar as suas conclusões.

A identificação de cada elemento do modelo em um texto envolve uma minuciosa análise, pois depende de como as ideias se interligam e assumem diferentes funções na composição desse texto. Desse modo, uma mesma frase ou palavra pode, em uma situação funcionar como um determinado elemento do modelo e, em outra, assumir uma nova função.

A Figura 1, abaixo, mostra o layout estrutural de argumento proposto por Toulmin, contendo todos os elementos por ele previstos.

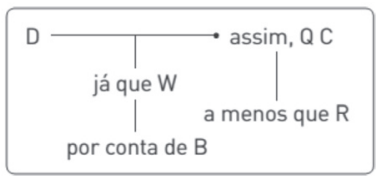

Figura 1: layout de Toulmin para argumentos (Toulmin, 2006).

Como discutido por Vieira (2007), uma das questões centrais na literatura sobre argumentação é como o discurso argumentativo pode ser reconstruído de modo que todos os seus aspectos estruturais relevantes possam ser destacados. Nesse contexto, se insere o Padrão de Argumento de Toulmin (2006).

Como atestam Nascimento e Vieira (2009), principalmente pelo seu caráter normativo, que permite identificar um enunciado como um argumento ou não, tendo-se em vista os elementos que o compõem, o padrão promove certa facilidade ao processo de análise de situações argumentativas. Nesse sentido, o TAP tornou-se uma ferramenta muito utilizada em pesquisas voltadas para a investigação da "argumentação científica" produzida por alunos em situações de ensino (Jiménez-Aleixandre et al., 1998; Capecchi e Carvalho, 2000; Scarpa et al., 2017). Algumas dessas pesquisas contribuíram de forma bastante significativa para consolidar tal modelo como um instrumento de análise neste campo do conhecimento (Jiménez-Aleixandre et al., 2000; Erduran et al., 2004).

O Modelo de Toulmin oferece a possibilidade de ressaltar o papel das evidências e dos conhecimentos teóricos na elaboração de explicações causais. De fato, o conhecimento científico se faz diferente de outras formas de saber, pois enunciados que representam conclusões ou hipóteses não se constituem em meras opiniões, devendo estar sustentados em provas, dados empíricos ou respaldo de natureza teórica.

Entretanto, apesar de bastante utilizado em pesquisas na área de Ensino de Ciências, são apontadas algumas limitações do modelo tendo-se em vista as análises pretendidas, as quais têm sido discutidas e "contornadas". Em várias situações, a amplitude das categorias previstas pelo modelo de Toulmin pode proporcionar dificuldade em sua aplicação aos dados de pesquisa, inibindo a distinção entre um elemento constituinte e outro. Isso tem gerado alterações em sua proposta original (Erduran, 2008; Erduran et. al., 2004) ou, mesmo, a 
sua utilização como inspiração para originar outros esquemas analíticos (Duschl, 2008).

Sobre a amplitude das categorias do modelo (Duschl, 2008), Garcia- Mila et al. (2013) observam que, apesar de tal limitação, o TAP é bastante proveitoso para a análise de pequenas estruturas de argumentos em que não se torna necessário distinguir entre si alguns dos elementos previstos.

Erduran (2007) discute sobre a dificuldade na distinção entre dados, garantias de inferência e apoio, considerando a análise das falas de alunos em interação. Para lidar com este problema metodológico, observa que alguns autores têm agrupado dados, garantias e apoios em um único elemento, entendido como "justificativa" para a conclusão (Erduran et. al., 2004; Zohar e Nemet, 2002). Ressalta-se que isso se torna oportuno quando as diferenças entre os argumentos analisados recaem nas relações entre conclusões, refutadores e qualificadores.

Jiménez-Aleixandre et al. (1998), por sua vez, propuseram uma ampliação do que Toulmin, em seu modelo, define como dado. Os autores diferenciam dado fornecido (DF) de dado obtido (DO). O primeiro é aquele que chega aos alunos por intermédio do professor, livro-texto ou roteiro de experimento, por exemplo. O segundo é advindo de situações experimentais. Este último pode ser subclassificado, ainda, em: dado empírico (DE), como no caso dos que procedem de uma experiência no laboratório, e dado hipotético (DH), quando se trata de uma construção mental para uma investigação que se tem em plano.

Como o foco do padrão proposto por Toulmin é a estrutura do argumento, o contexto de produção não é por ele levado em conta. Outro aspecto nessa direção é o de que o padrão expressa o produto (o argumento) e não o processo argumentativo (a argumentação), de modo que o caráter dialogal não é valorizado. Todavia, pesquisas focando as interações em sala de aula o tem utilizado com valiosas discussões, considerando como os argumentos resultam dos debates entre os sujeitos deste ambiente (Jimenez-Aleixandre et al., 2000; Erduran et al., 2004; Osborne et al., 2004; Ferraz e Sasseron, 2017a; Ferraz e Sasseron, 2017b; Ratz e Motokane, 2016, por exemplo). Nessa perspectiva, a percepção da estrutura e do conteúdo do argumento elaborado é favorecida pela compreensão do seu processo de produção no contexto específico da argumentação.

Seguindo essa linha, em nossa pesquisa utilizamos o TAP tanto para a análise dos argumentos expressos nos textos dos alunos, como para o processo de produção dos argumentos ao longo das interações. Nesse sentido, identificamos como os elementos propostos no Modelo de Toulmin eram trazidos pelos alunos e solicitados pelo professor de modo a, gradativamente, irem compondo argumentos consistentes, tanto do ponto de vista estrutural, quanto do ponto de vista do conteúdo que se expressava nos seus elementos constituintes. Assim, foi possível perceber como as ideias dos alunos se aprimoravam na elaboração dos argumentos, em função da exposição às ideias dos colegas e intervenções do professor, considerando o plano social da sala de aula. Tratamos, nesse ponto, portanto, do processo argumentativo instaurado em uma das fases da SEI planejada e desenvolvida na pesquisa.

O modelo proposto por Toulmin (2006) possibilita, ainda, que a qualidade de um argumento seja avaliada. Como argumentam Garcia-Milla et al. (2013), justamente por focar na estrutura, o TAP permite examinar a complexidade dos argumentos. Isso é frequentemente verificado com base nas combinações dos elementos previstos no modelo, como discutido por Erduran et al. (2004). Argumentos que se constituem em combinações com um maior número de elementos são considerados mais sofisticados que aqueles que apresentam apenas os elementos fundamentais, ou seja, dados, garantias de inferência e conclusões. Sá et al. (2014), por sua vez, observaram como oportuno considerar também a frequência com que os elementos aparecem no argumento e não apenas a combinação entre eles.

Garcia-Milla et al. (2013) chamam atenção para a presença de refutadores como um valioso indicativo da qualidade dos argumentos, tendo em vista a discussão apresentada por Kuhn (1991). Esta autora considera que contra-argumentos e refutadores expressam habilidades mais complexas no discurso argumentativo, tendo em vista que, quando indivíduos levam em conta uma refutação, mostram a percepção das limitações de suas asserções, adiantando-se ao possível contra-argumento do seu interlocutor.

A discussão sobre a qualidade dos argumentos acima apresentada orientou o nosso olhar para a análise dos argumentos verificados em nossa pesquisa.

\section{A Sequência de Ensino Investigativa}

A estrutura da SEI inspira-se no ciclo investigativo de Pedaste et al. (2015), apresentando as fases de: orientação, conceitualização, investigação, conclusão e discussão. O ciclo investigativo proposto pelos autores é composto pelas cinco fases acima informadas, sendo que algumas delas podem ser divididas em sub-fases, como será explicado oportunamente. A análise apresentada neste artigo envolve as discussões instauradas na fase de conceitualização/investigação. A seguir, apresentamos as principais fases da SEI, considerando como elas se materializaram em nossa pesquisa como um todo, tendo-se em vista a temática envolvida.

a) ORIENTAÇÃO: De acordo com Pedaste et al. (2015), esta fase envolve o processo de estimular a curiosidade dos alunos sobre um certo tópico e introduzir um desafio de aprendizagem por meio da apresentação de um problema. É também o momento no qual são levantadas as concepções prévias dos alunos. Portanto, nesta fase inicial, foram introduzidos o tema e aspectos gerais da SEI, a fim de mobilizar os alunos a se engajarem nas atividades que seriam posteriormente desenvolvidas. Feito isso, foi apresentada a questão central da sequência: Como uma usina termoelétrica produz energia? Nessa perspectiva, o propósito foi considerar os aspectos envolvidos no funcionamento da termoelétrica como também as suas consequências 
ambientais. A partir daí, as concepções prévias dos alunos foram exploradas.

b) CONCEITUALIZAÇÃO e INVESTIGAÇÃO: Em nossa SEI essas fases ocorreram conjuntamente como descrevemos a seguir.

De acordo com Pedaste et al. (2015), na fase de conceitualização se dá o processo de elaborar questões baseadas em teorias e/ou gerar hipóteses, considerando o problema colocado na fase de orientação. Neste sentido, a conceitualização pode apresentar duas sub-fases: questionamentos e geração de hipóteses. As questões que surgem nesta fase desencadeiam-se de uma questão específica de pesquisa ou de questões mais abertas sobre um determinado domínio do conhecimento; trata-se de questões investigáveis. A geração de hipóteses, por sua vez, envolve a declaração de possíveis respostas às tais questões.

Vale ressaltar que, como argumentam os autores, a conceitualização é, sobretudo, um processo de entendimento de um conceito ou conceitos relativos ao problema iniciado. Tal entendimento se dá em meio à elaboração de questões e hipóteses. Neste sentido, é possível entender que as intervenções do professor nesta fase devem envolver a retomada de conceitos anteriores e a introdução de outros novos.

A conceitualização corresponde a uma fase em que se prepara para a investigação que se instaura na fase seguinte, ou seja, os questionamentos e hipóteses gerados nesta fase, bem como os conceitos retomados e /ou introduzidos, mobilizam o planejamento e a execução dos experimentos ou observações sistemáticas e a decorrente interpretação dos dados obtidos. Nessa perspectiva, é comum tais fases - conceitualização e investigação - chegarem a se intercalar, de modo a flexibilizar os seus limites. Os autores observam, considerando casos dispostos na literatura, que o ciclo pode, inclusive, se iniciar com a fase de conceitualização e ter vários pequenos ciclos entre esta fase e a de investigação.

No caso de nossa pesquisa, a SEI apresenta uma questão ampla que não encontra resposta por meio da análise de dados coletados de uma única atividade de experimentação ou observação sistemática. Ela envolveu, portanto, dois experimentos os quais geraram espaço para circulação de ideias a fim de que os alunos pudessem nas fases de conclusão e discussão responder à questão central e defender seus pontos de vista.

O desenvolvimento de ambos os experimentos, intercalados entre si por explanações teóricas por parte do professor, bem como permeados por intervenções que guiavam a elaboração de questões e hipóteses, envolveu as fases de conceitualização e investigação. Nesse sentido, ao longo dos experimentos, foram trabalhadas ideias fundamentais da Termoquímica, ao tempo em que dados eram coletados, tratados e analisados, configurando-se aí os momentos de investigação. Para Pedaste et al. (2015), na investigação ocorre o processo de planejar a exploração ou a experimentação, bem como coletar e analisar os dados baseando-se no plano estabelecido.

A seguir descrevemos as atividades desenvolvidas nesta fase em que conceitualização e investigação coexistem.
Na primeira atividade, uma experimentação demonstrativa de como funciona um gerador termoelétrico foi utilizada para retomar e construir conceitos fundamentais para o desenvolvimento da SEI, mobilizando a elaboração de perguntas pelos alunos, ao tempo em que outras eram propostas pelo professor. A experimentação consistiu na geração de energia elétrica, através de um gerador termoelétrico, por meio da energia térmica em transição, utilizando-se de uma placa de Peltier entre uma fonte fria e uma fonte quente (https://www.youtube.com/ watch? $=$ wLrXYMJs-q8).

Usinas termoelétricas utilizam diversos princípios para seu funcionamento. O que vemos na placa de Peltier é um deles. Ela apresenta condutores ou semicondutores. Para o experimento no Ensino Médio, consideram-se os metais como condutores. É necessário que haja troca de energia entre uma fonte quente e uma fonte fria estando, entre estas, a placa de Peltier para que haja deslocamento de seus elétrons. Então, o fluxo de energia na forma de calor se alinha ao fluxo de elétrons. A transferência de energia entre tais sistemas (fontes quente e fria), intercalados pela placa, provoca esse fluxo de elétrons no metal.

Segundo Callister (2002), a ligação metálica acontece pela ocorrência de uma nuvem de elétrons de valência que passam a se comportar como elétrons livres, o que possibilita que seja gerada uma corrente elétrica em função de uma diferença de temperatura a que o metal seja submetido. No caso do aparato experimental aqui descrito, é isto que possibilita movimentar uma pequena turbina que se liga a placa de Peltier (ver Quadro 1).

O objetivo foi ensinar aos alunos que energia térmica produz energia elétrica. A conversão de calor em eletricidade ou eletricidade em calor é chamada de termoeletricidade. Este é um conceito não trivial. É uma associação incomum no cotidiano e pouco explorada, mesmo na escola. Num momento posterior, buscou-se discutir as reações de combustão como geradoras primárias de energia em uma termoelétrica, o que ocorre no tipo de usina a ser implantada na cidade em questão. Assim,

Quadro 1 - Ficha para observação experimental de um Gerador Termoelétrico

$\begin{aligned} & \text { Material e Reagente } \\ & \text { - placa de Peltier } \\ & \text { - pasta térmica (a mesma } \\ & \text { usada em computadores) } \\ & \text { - duas latinhas vazias de azeite } \\ & \text { - motor de drive de DVD } \\ & \text { - alguns elásticos de escritório }\end{aligned}$
$\begin{aligned} & \text { Figura 2: Esquema de gerador } \\ & \text { termoelétrico (Manual do Mundo). }\end{aligned}$
$\begin{aligned} & \text { Procedimento } \\ & \text { meio das duas latinhas. Aperte bem com os elásticos, para que a } \\ & \text { placa fique grudada nas latas. Coloque água quente do lado positivo } \\ & \text { do fio (vermelho) e água fria do lado negativo (preto). Pegue o seu } \\ & \text { motorzinho de DVD e faça o teste final! }\end{aligned}$

Fonte: (https://www.youtube.com/watch?v=wLrXYMJs-q8) 
o professor dispendeu um tempo necessário na construção de argumentos nessa fase. Consideramos esta etapa essencial para obter êxito nos outros momentos da sequência investigativa. No Quadro 1, apresentamos a ficha entregue aos alunos no momento do desenvolvimento do experimento.

As questões problematizadoras foram as seguintes:

1) Qual a principal variável para o gerador termoelétrico funcionar?

2) O que faço para ter uma maior geração de eletricidade?

3) A energia, na forma de calor, é totalmente aproveitada no aparelho para gerar eletricidade?

4) $\mathrm{O}$ que acontece quando um fluxo de energia na forma de calor atravessa um metal? O que será gerado?

Na segunda atividade desta fase, uma imagem de uma planta simplificada de uma termoelétrica foi utilizada para explicar conhecimentos de termoquímica, como por exemplo, a utilização da energia de uma combustão para gerar vapor d'água e, em seguida, condensá-la. Além disso, foram introduzidos os conceitos de processo endotérmico e processo exotérmico, bem como a ideia de eficiência em uma transferência calórica.

$\mathrm{Na}$ terceira atividade desta fase, desenvolveu-se o segundo experimento em que os alunos receberam uma ficha de observação para determinar o calor de reação do peróxido de hidrogênio, conforme descrito em Braathen et al. (2008). Cinco grupos foram montados e cada um recebeu o material para confecção de um calorímetro, avaliando a temperatura inicial do sistema. Em seguida, foram orientados a proceder com a reação e, posteriormente, elaborarem suas conclusões, desenvolvendo a argumentação.

c) CONCLUSÃO: Nesta fase, foram elaboradas as conclusões a partir dos dados obtidos na fase anterior, de forma a responder à questão central da SEI. Neste momento foi discutido o texto "A sociedade e a usina termoelétrica", para consolidar as relações Ciência, Tecnologia e Sociedade.

d) DISCUSSÃO: Nesta etapa, foi desenvolvida uma discussão sobre toda a investigação. Pedaste et al. (2015) consideram que tal fase é necessária para que os alunos compreendam a natureza do trabalho científico em que estiveram engajados. Os autores observam ainda que a fase de discussão (a qual inclui comunicação e reflexão) está potencialmente presente em cada ponto da aprendizagem baseada em investigação e conecta todas as outras fases. Portanto, ela pode ocorrer a qualquer tempo do ciclo investigativo ou apenas em sua fase final.

\section{Procedimentos de coleta e análise de dados}

A sequência de ensino investigativa foi desenvolvida em uma turma, composta por 25 alunos, da $2^{\circ}$ Série do curso Integrado Técnico em Química de uma escola pública da Rede Federal de Ensino. A turma foi dividida em cinco grupos e um grupo de cinco alunos foi tomado como referência para análise do processo argumentativo. Tal grupo foi escolhido por se mostrar bastante ativo desde as discussões iniciais. No entanto, os demais grupos tiveram orientações semelhantes ao grupo analisado quanto à migração das concepções alternativas ao conhecimento científico.

Os dados foram obtidos por meio de gravações em áudio e vídeo, bem como pelos roteiros de experimentos os quais propunham questões a serem respondidas por escrito pelos alunos. Consideramos, assim, a produção conjunta dos argumentos dos alunos do grupo tomado para análise em interação com o professor, e dos textos produzidos por cada aluno da turma ao final da atividade, em respostas às questões propostas. Os registros em áudio e vídeo foram transcritos e, juntamente aos escritos, submetidos à análise por meio do Padrão de Argumento de Toulmin. Nesse sentido, buscamos identificar nesses textos, os elementos propostos no padrão, de modo a caracterizar a estrutura dos argumentos que se apresentavam. Aliado à análise da estrutura, verificamos o conteúdo dos argumentos, de modo a perceber a apropriação das concepções científicas pelos alunos.

Os argumentos produzidos pelos alunos individualmente, como resposta por escrito a cada questão proposta no roteiro do experimento, após a discussão nos pequenos grupos, foram agrupados entre si de acordo com suas semelhanças de conteúdo e estrutura. Para cada tipo de argumento foi atribuído um valor percentual correspondente à sua frequência em relação ao total da amostra (25 alunos).

Além da caracterização da estrutura dos argumentos, buscamos verificar as possíveis diferenciações entre eles, tendo em vista as combinações entre os seus elementos, as quais são indicativas da qualidade de um argumento, conforme a discussão apresentada na seção em que apresentamos tal padrão.

\section{Resultados e Discussão}

A proposta do experimento desenvolvido na primeira parte da segunda fase da SEI foi explorar a ideia de que os supercondutores em que se constitui a placa de Peltier possuem elétrons livres e, devido à condutividade térmica, produzida por uma diferença de temperatura, gerará um fluxo ordenado de elétrons. Nesta parte, os alunos apresentaram suas concepções considerando os dados experimentais e os conhecimentos escolares anteriores, sobretudo os da $1^{\circ}$ Série do Ensino Médio e, assim, foi desenvolvida uma discussão sobre as hipóteses pautadas por eles para explicar o fenômeno em discussão. Nesse sentido, é possível verificar um movimento em que os olhares dos alunos focam, ora aspectos particulares do fenômeno, ora as generalizações da ciência. Esse movimento é importante para a constituição de argumentos em que os dados experimentais se aliam às conclusões por meio de conhecimentos teóricos, ou seja, os denominados conhecimentos de base e/ou garantias de inferência, de acordo com a estrutura proposta por Toulmin (2006).

Todo o processo argumentativo durou 13 minutos e 28 segundos, sendo dividido em dois episódios intitulados, respectivamente, por: "Princípios de termoquímica na termoelétrica: como obter mais eletricidade" e "A condução térmica e 
a condução elétrica se aliam". A seguir, apresentamos excertos das discussões que se inserem nos dois episódios e uma análise sobre como elementos constituintes dos argumentos são gerados ao longo das interações. Nessa análise das interações discursivas, buscamos evidenciar, portanto, a construção conjunta dos argumentos, explicitando como estes são gradativamente configurados. Nesse sentido, nosso olhar recai também nas intervenções do professor, iluminando o seu investimento para que os alunos apreendam aspectos fundamentais à compreensão do fenômeno e elaboração de argumentos.

A discussão apresentada no Quadro 2, referente ao primeiro episódio (Princípios da Termoquímica na Termoelétrica: como obter mais eletricidade?), evidencia como os alunos do grupo investigado vão elaborando conjuntamente os argumentos para

Quadro 2: Episódio: "Princípios de termoquímica na termoelétrica: Como obter mais eletricidade?

\begin{tabular}{|c|c|c|c|c|}
\hline $\begin{array}{l}\text { Turnos } \\
\text { de fala }\end{array}$ & Locutor & Falas & $\begin{array}{l}\text { Ações do professor e dos alunos em relação à } \\
\text { emergência dos elementos do TAP }\end{array}$ & $\begin{array}{c}\text { Sujeitos da } \\
\text { interação }\end{array}$ \\
\hline 1 & Professor & $\begin{array}{l}\text { Há uma migração de energia de um lado } \\
\text { para outro. Qual seria esse lado? }\end{array}$ & $\begin{array}{l}\text { Propõe um problema (1): Fomenta a articulação entre } \\
\text { dados e conhecimentos teóricos (conhecimentos de } \\
\text { base ou garantias de inferência). }\end{array}$ & \multirow[t]{9}{*}{ Professor- alunos } \\
\hline 2 & Aluno 1 & Seria do calor pro frio. & $\begin{array}{l}\text { Apresenta conhecimento teórico - garantia de } \\
\text { inferência. }\end{array}$ & \\
\hline 3 & Professor & $\begin{array}{l}\text { Do quente para o frio. Por que é geralmente } \\
\text { neste sentido? }\end{array}$ & $\begin{array}{l}\text { Explora conhecimento teórico - a } 2^{a} \text { Lei da } \\
\text { Termodinâmica - garantia de inferência. }\end{array}$ & \\
\hline 4 & Aluno 2 & $\begin{array}{l}\text { Geralmente o quente só perde e o frio só } \\
\text { tende a ganhar. }\end{array}$ & $\begin{array}{l}\text { Apresenta conhecimento teórico-garantia de } \\
\text { inferência. }\end{array}$ & \\
\hline 5 & Professor & $\begin{array}{l}\text { Isto tem a ver com princípios de } \\
\text { termoquímica. }\end{array}$ & $\begin{array}{l}\text { Investe no aprofundamento do conhecimento teórico } \\
-2^{\mathrm{a}} \text { Lei da Termodinâmica - garantia de inferência. }\end{array}$ & \\
\hline 6 & Aluno 1 & $\begin{array}{l}\text { Nós estudamos na Física... condução de } \\
\text { calor!! }\end{array}$ & $\begin{array}{l}\text { Apresenta conhecimento teórico-garantia de } \\
\text { inferência. }\end{array}$ & \\
\hline 7 & Professor & $\begin{array}{l}\text { A energia vai migrar do ambiente mais } \\
\text { quente para o ambiente mais frio. }\end{array}$ & $\begin{array}{l}\text { Sintetiza/informa o conhecimento teórico - } 2^{\mathrm{a}} \text { Lei da } \\
\text { Termodinâmica - garantia de inferência. }\end{array}$ & \\
\hline 8 & Aluno 1 & $\begin{array}{l}\text { A energia vai sair da plaquinha (Peltier) } \\
\text { para turbininha. }\end{array}$ & Apresenta hipótese/ conclusão. & \\
\hline 9 & Professor & Vão discutindo ai; volto já! & & \\
\hline 10 & Aluno 5 & $\begin{array}{l}\text { Então, está ocorrendo a passagem de } \\
\text { elétrons do quente para a placa, mas não } \\
\text { tá chegando no frio... }\end{array}$ & Gera dados. & \multirow[t]{13}{*}{ Aluno - Aluno } \\
\hline 11 & Aluno 3 & A placa está redirecionando para turbina!! & Apresenta hipótese/conclusão. & \\
\hline 12 & Aluno 1 & $\begin{array}{l}\text { O que faço para ter uma maior geração de } \\
\text { eletricidade? (Lendo a pergunta). }\end{array}$ & Apresenta um problema (2). & \\
\hline 13 & Aluno 5 & $\begin{array}{l}\text { Aumenta o calor!! Quanto mais calor mais } \\
\text { energia (todos juntos). }\end{array}$ & $\begin{array}{l}\text { Apresenta argumento composto de hipótese/ } \\
\text { conclusão e garantia de inferência. }\end{array}$ & \\
\hline 14 & Aluno 3 & $\begin{array}{l}\text { Não necessariamente o outro precisa ser } \\
\text { gelado! }\end{array}$ & Complementa conclusão. & \\
\hline 15 & Aluno 2 & $\begin{array}{l}\text { Exatamente! Não necessariamente o outro } \\
\text { precisa ser gelado, mas numa temperatura } \\
\text { normal! }\end{array}$ & Complementa conclusão. & \\
\hline 16 & Aluno 5 & Daí já dá para trocar de calor! & Complementa conclusão. & \\
\hline 17 & Aluno 3 & $\begin{array}{l}\text { Tem de deixar o quente mais quente que } \\
\text { ele já tá. }\end{array}$ & Apresenta hipótese/Conclusão. & \\
\hline 18 & Aluno 4 & $\begin{array}{l}\text { Em que você se baseou para chegar a essa } \\
\text { conclusão? (Lendo a pergunta). }\end{array}$ & Solicita conhecimento teórico - garantia de inferência. & \\
\hline 19 & Aluno 1 & $\begin{array}{l}\text { Se há uma passagem de elétrons do quente } \\
\text { para o frio é só aumentar a temperatura! }\end{array}$ & $\begin{array}{l}\text { Apresenta argumento composto de garantia de } \\
\text { inferência e conclusão. }\end{array}$ & \\
\hline 20 & Aluno 5 & $\begin{array}{l}\text { A energia, na forma de calor, é totalmente } \\
\text { aproveitada no aparelho para gerar } \\
\text { eletricidade? (Lendo a pergunta). }\end{array}$ & Apresenta um problema (3). & \\
\hline 21 & Alunos & $\begin{array}{l}\text { Eu creio que não! Eu também creio que } \\
\text { não!! }\end{array}$ & Apresenta hipótese/conclusão hipótese. & \\
\hline 22 & Alunos 1 & $\begin{array}{l}\text { Parte da energia se perde antes de chegar } \\
\text { no motor!! }\end{array}$ & Apresenta hipótese/ conclusão. & \\
\hline
\end{tabular}


as questões propostas pelo professor. Até o turno 8, o docente investe na interação com os alunos a fim de assegurar que eles estariam conscientes do princípio envolvido nas explicações que construiriam para os resultados experimentais. Ele conduz tal discussão com uma abordagem interativa/de autoridade ${ }^{1}$, até se afastar e conferir autoridade aos alunos para que eles mesmos discutissem entre si e respondessem as questões propostas.

O Quadro 2 compreende 5 colunas. A primeira apresenta a ordem dos turnos de fala; a segunda se refere aos locutores, ou seja, aqueles que detêm os respectivos turnos de fala; a terceira apresenta as falas dos sujeitos/locutores; a quarta apresenta as ações do professor e dos alunos em relação aos elementos do Modelo de Toulmin que aparecem em suas falas e, por fim, a quinta informa os sujeitos da interação, se professor e alunos ou alunos entre si.

O investimento do professor em estabelecer com os alunos conhecimentos teóricos para suprir a análise do fenômeno investigado mostra como tal caminho não é algo simples, embora tenha sido frutífero. Na discussão que desenvolvem entre si, os alunos conseguem articular conhecimento teórico (correspondente à $2^{\mathrm{a}}$ Lei da Termodinâmica) a dados experimentais, refletir sobre tal relação, elaborar hipóteses/conclusões para as questões propostas e elaborar argumentos (turnos 13 e 19) compostos por conclusão e garantia de inferência. Vale ressaltar que, durante toda a etapa de conceitualização, o professor investiu na construção de conceitos fundamentais da termoquímica, os quais seriam aprofundados e articulados na investigação da etapa seguinte.

Vamos verificar mais detidamente os argumentos formados conjuntamente pelos alunos do grupo, tendo-se em vista as questões (problemas) propostas pelo professor:

Questão (Problema 1): Há uma migração de energia de um lado para outro. Qual seria esse lado? (Turno 1).

Com tal questão, o professor solicita que os alunos identifiquem no aparato experimental o sentido do fluxo de energia. Desta forma, os alunos devem apresentar as hipóteses/ conclusões, as quais para serem elaboradas demandam uma articulação entre os conhecimentos teóricos (leis, conceitos, princípios etc. da ciência) e evidências experimentais. Assim, os alunos buscam identificar o sentido do fluxo de energia no aparato, recorrendo aos conhecimentos da termodinâmica. Considerando-se o princípio de que o fluxo de energia na forma de calor flui no sentido do corpo quente para o corpo frio e de que, no aparato experimental, há a indicação da estrutura quente $(\mathrm{Q})$ e da estrutura fria $(\mathrm{F})$, conclui-se que a água quente cederá energia, na forma de calor, para a água fria. No turno 8, A1, por sua vez, apresenta a hipótese de que "A energia vai sair da plaquinha (Peltier) para turbininha". Todavia, ao que se mostra, os alunos não têm ainda clareza de que a diferença de temperatura, a qual possibilita a transferência de energia da fonte quente para a fonte fria (da água quente de uma latinha para a água fria da outra), passando pela placa de Peltier, não proporcionará a passagem de elétrons de uma fonte à outra. Os elétrons livres presentes na placa de Peltier se orientam graças à passagem de energia na forma de calor, movimentando-se ao longo dos fios, da placa à turbininha (motor de DVD). Desse modo, não haverá passagem de elétrons da fonte quente para a fria como é desejado/sugerido pelo Aluno 5, posteriormente, no turno 10 ("Então, está ocorrendo a passagem de elétrons do quente para a placa, mas não tá chegando no frio....”). Tampouco, o fluxo de energia na forma de calor no sentido placa-turbina será, diretamente, o responsável pelo movimento do cata-vento da turbina, como considerado pelo Aluno 3, no turno 11 ("A placa está redirecionando para turbina!!").

Assim, a ideia de que a energia (elétrica) sairá da plaquinha e chegará à turbininha não se apresenta ainda de forma adequadamente conectada aos conhecimentos teóricos, sendo certamente inferida por A1 em função da percepção do aparato experimental em si, uma vez que se espera que o cata-vento da turbininha gire e isso, certamente, requererá energia elétrica. Não fica claro, ainda, de qual energia A1 está falando (se térmica ou elétrica), pois a conexão entre energia térmica e elétrica no experimento está sendo posta em discussão naquele momento, iniciando-se aí a sua elaboração. Por outro lado, pode-se ter a ideia de que, como a placa se torna quente, enquanto a turbininha é fria, haverá passagem de calor (e de elétrons) também neste sentido.

De acordo com o modelo proposto por Toulmin na Figura 2, temos, então:

Dado

O design do experimento

$\mathrm{Ou}$, a placa é quente e a turbininha é fria

\section{Conclusão/Hipótese}

A energia vai sair da plaquinha (Peltier) para turbininha. (Turno 8)

Garantias de inferência (O sentido do fluxo de calor/energia): Do calor para o frio (do quente para o frio) (Turno 2)

Geralmente o quente só perde e o frio só tende a ganhar. (Turno 4)

A energia vai migrar do ambiente mais quente para o ambiente mais frio. (Turno 7)

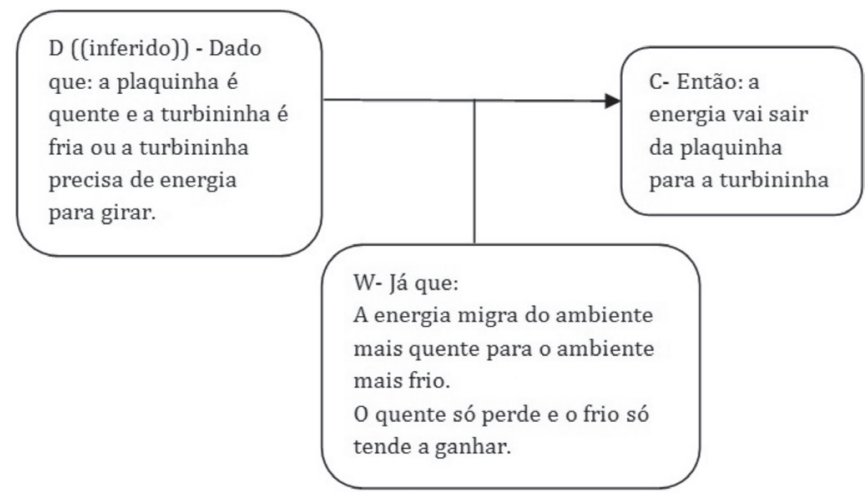

Figura 3: Esquema de Toulmin para a resposta à questão: Há uma migração de energia de um lado para outro. Qual seria esse lado? 
Após a elaboração dessa hipótese, os alunos do grupo investigado passam a verificar discrepâncias entre os resultados encontrados e os previstos, porém uma nova questão (Problema 2) é colocada em pauta, no turno 12, pelo Aluno 1.

Questão (Problema 2): O que faço para ter uma maior geração de eletricidade? (turno 12)

Logo após a apresentação dessa questão pelo Aluno 1, no turno 12, o Aluno 5 apresenta no turno seguinte (13) uma resposta que corresponde a um argumento composto de conclusão/ hipótese e garantia de inferência (Aumenta o calor!! Quanto mais calor, mais energia). A partir da ideia de que quanto mais calor mais energia, o aluno infere que se deve aumentar o calor para que haja mais passagem de energia. O conhecimento que promove a conclusão/hipótese do Aluno 5 vai sendo complementado nos turnos seguintes até que, no turno 17, o Aluno 3 apresenta a sua hipótese seguindo o mesmo raciocínio do Aluno 5 (Tem que deixar o quente mais quente que ele já tá). No turno 19, o Aluno 1 apresenta também um argumento semelhante ao do Aluno 5 (Se há uma passagem de elétrons do quente para o frio é só aumentar a temperatura!), tendo-se em vista a solicitação do Aluno 4 pelos conhecimentos teóricos, apresentada no turno anterior (Em que você se baseou para chegar a essa conclusão?).

$\mathrm{O}$ argumento produzido ao longo dessa cadeia de interações pode ser assim esquematizado.

Conclusão: (Para ter uma maior geração de eletricidade) tem que:

Aumentar o calor (Turno 13)

Deixar o quente mais quente do que ele já tá (Turno 17)

É só aumentar a temperatura (Turno 19)

\section{Garantia de inferência}

Quanto mais calor, mais energia (Turno 13)

(Se) há uma passagem de elétrons do quente para o frio (...) (Turno 19)

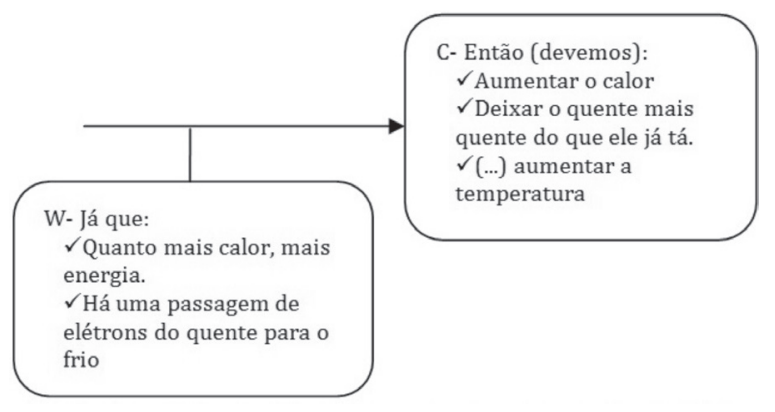

Figura 4: Esquema de Toulmin para a resposta à questão: O que faço para ter uma maior geração de eletricidade?

Como podemos verificar, ao longo da interação os alunos vão retomando o princípio de que a energia na forma de calor flui do corpo mais quente para o mais frio; todavia, persiste a ideia de que os elétrons fluem também da água quente para a fria. Isso evidencia o quanto a relação entre energia térmica e elétrica necessita de mais discussão.
No turno 20, o Aluno 5 apresenta uma nova questão (Problema 3):

Questão (Problema 3): “A energia, na forma de calor, é totalmente aproveitada no aparelho para gerar eletricidade?"

Para tal questão são formuladas hipóteses/conclusões, nos turnos seguintes (21 e 22), sem que sejam apresentados os elementos justificatórios. Os alunos consideram que a energia para geração de eletricidade não é totalmente aproveitada, que "parte da energia se perde antes de chegar ao motor", porém não justificam seus pontos de vista. Nesse sentido, não se tem um argumento, visto que a argumentação presume ponto de vista justificado.

É possível verificar que os alunos necessitaram de uma condução de autoridade por parte do professor para interpretação dos fenômenos observados no experimento. Nos turnos 3,5 e 7 , o professor busca estabelecer na discussão o princípio relativo ao sentido do fluxo de energia, de modo que os alunos o utilizassem na interpretação do experimento; todavia, a relação fluxo de energia na forma de calor - fluxo de energia na forma de eletricidade, ainda seria mais explorada para que se compreendesse bem o funcionamento da turbininha no aparato experimental. Isto coopera com diversos estudos que apontam que o experimento por si só não produz conhecimento, na perspectiva da ciência escolar (Carrascosa et al., 2006; Hodson, 1994, 2014; Mortimer, 1994).

Desta forma, o professor empreendeu tempo razoável para que os alunos buscassem chegar a hipóteses cientificamente aceitáveis na relação entre energia na forma de calor e geração de eletricidade. Isto se reflete também na estrutura dos argumentos analisados conforme modelo de Toulmin. Observa-se um argumento completo referente à primeira questão (problema 1), um outro incompleto por falta de apresentação explícita de um dado (questão/problema 2) e a questão/problema 3 sem argumento como resposta, pois houve apenas apresentação de um enunciado sem justificativa.

Neste episódio, ficou claro que os alunos retomam concepções sobre a passagem de energia do quente para o frio e articulam tais concepções de modo a inferirem que aumentando a temperatura será produzida mais energia. Porém, aspectos mais sofisticados dos conceitos científicos necessitavam de melhor elaboração, como a compreensão de que a diferença de temperatura é que gerará um maior fluxo de calor, o qual proporcionará uma maior movimentação dos elétrons livres na placa, os quais se dirigem rumo à turbininha, pelos fios metálicos.

Passemos, agora, à discussão do $2^{\circ}$ episódio, cujo excerto encontra-se no Quadro 3. A discussão corresponde ao momento em que o professor retorna ao grupo investigado e explora as ideias que os cinco alunos elaboraram na discussão que mantiveram entre si, bem como investe ainda mais na elaboração da compreensão do sentido do fluxo de energia na forma de calor, buscando relacioná-lo, adequadamente, à condução elétrica. 
Quadro 3: A condução térmica e a condução elétrica se aliam.

\begin{tabular}{|c|c|c|c|}
\hline Turno & Locutor & Falas & $\begin{array}{l}\text { Ações do professor e dos alunos em relação à possível } \\
\text { emergência dos elementos do TAP }\end{array}$ \\
\hline 1 & Professor & Considere a placa de Peltier um supercondutor metálico!! & $\begin{array}{l}\text { Busca promover o avanço na compreensão dos } \\
\text { conhecimentos teóricos - propriedades dos metais }\end{array}$ \\
\hline 2 & Alunos 2 e 5 & O metal é um excelente condutor de calor! & Apresenta conhecimento teórico - garantia de inferência. \\
\hline 3 & Aluno 3 & $\begin{array}{l}\text { Se no lugar da placa fosse uma madeira ou plástico ele } \\
\text { não funcionaria por que o metal conduz melhor o calor!! }\end{array}$ & $\begin{array}{l}\text { Apresenta argumento composto por hipótese/conclusão e } \\
\text { garantia de inferência. }\end{array}$ \\
\hline 4 & Professor & $\begin{array}{l}\text { Vamos revisar? O que faço para ter uma maior geração } \\
\text { de eletricidade? }\end{array}$ & Propõe um problema (1) \\
\hline 5 & Alunos $2,3,5$ & Diferença de temperatura. & Apresenta conclusão. \\
\hline 6 & Professor & Como você chegou a essa conclusão? & $\begin{array}{l}\text { Explora a produção de argumento -relação entre } \\
\text { conclusão, dados experimentais e conhecimentos teóricos } \\
\text { (Conhecimento de base e/ou garantia de inferência). }\end{array}$ \\
\hline 7 & Aluno 1 & $\begin{array}{l}\text { (...) existe passagem de calor da latinha quente para } \\
\text { latinha fria e principalmente, nem todo o calor chega na } \\
\text { latinha do frio... }\end{array}$ & Apresenta dados. \\
\hline 8 & Aluno 4 & Acho que o calor se perde no percurso... & Apresenta hipótese/Conclusão. \\
\hline 9 & Aluno 2 & $\begin{array}{l}\text { Outra coisa que estávamos discutindo é que as latas } \\
\text { conduzem eletricidade }\end{array}$ & Apresenta conhecimento teórico - propriedade dos metais \\
\hline 10 & Professor & $\begin{array}{l}\text { Neste caso, como uma condução de calor gera uma } \\
\text { condução de eletricidade? }\end{array}$ & Propõe um problema (2) \\
\hline 11 & Alunos & $\begin{array}{l}\text { O metal é mais fácil de passar energia (discussão sem } \\
\text { chegar a uma conclusão) }\end{array}$ & Apresenta conhecimento teórico - propriedade dos metais \\
\hline 12 & Professor & $\begin{array}{l}\text { Então, por que tem condução de calor e de eletricidade? } \\
\text { Para isso me explique o que é uma ligação metálica!! }\end{array}$ & Propõe um problema (2) / Explora conhecimento teórico \\
\hline 13 & Alunos & $\begin{array}{l}\text { (...) agora temos de pensar, discutir um pouquinho... } \\
\text { (diálogos sem uma conclusão). }\end{array}$ & \\
\hline 14 & Professor & $\begin{array}{l}\text { Vamos pensar juntos: Diferença de calor gerou energia, } \\
\text { eletricidade! }\end{array}$ & Investe na produção de sentido aos dados experimentais \\
\hline 15 & Aluno 5 & Eles tentam trocar energia entre si até alcançar o equilíbrio & Apresenta conhecimento teórico \\
\hline 16 & Professor & Houve algum tipo de condução antes do equilíbrio? & Explora a relação entre dados e conhecimentos teóricos. \\
\hline 17 & Aluno 4 & Houve & Conclusão \\
\hline 18 & Aluno 5 & A troca de elétrons & Conclusão \\
\hline 19 & Professor & $\begin{array}{l}\text { Pense na placa de Peltier como um metal, um super metal!! } \\
\text { O que é um metal? }\end{array}$ & $\begin{array}{l}\text { Investe no aprofundamento de conhecimentos teóricos - } \\
\text { definição de metal }\end{array}$ \\
\hline 20 & Alunos & $\begin{array}{l}\text { Discutindo e não sabendo uma definição exata... (3 } \\
\text { minutos) }\end{array}$ & \\
\hline 21 & Professor & Que tipo de ligação tem no metal? & $\begin{array}{l}\text { Investe retomada de conhecimentos teóricos - estrutura } \\
\text { dos metais }\end{array}$ \\
\hline 22 & Aluno 1 & lônica? & Apresenta conhecimento teórico \\
\hline 23 & Professor & Não! & $\begin{array}{l}\text { Investe na retomada de conhecimentos teóricos-estrutura } \\
\text { dos metais }\end{array}$ \\
\hline 24 & Aluno 3 & É um compartilhamento de elétrons basicamente! & Apresentando conhecimento teórico - estrutura dos metais \\
\hline 25 & Professor & $\begin{array}{l}\text { Não, compartilhamento é ligação covalente! O que tem } \\
\text { um metal de especial que forma uma ligação metálica? }\end{array}$ & $\begin{array}{l}\text { Investe na retomada de conhecimentos teóricos-estrutura } \\
\text { dos metais }\end{array}$ \\
\hline 26 & Aluno 1 & Ele doa? & $\begin{array}{l}\text { Apresentando conhecimentos teóricos - estrutura dos } \\
\text { metais }\end{array}$ \\
\hline 27 & Professor & Ele doa por que tem? & $\begin{array}{l}\text { Investe na retomada de conhecimentos teóricos-estrutura } \\
\text { dos metais }\end{array}$ \\
\hline 28 & Aluno 1 & Cátions, ele é um cátion? & Apresenta conhecimento teórico - estrutura dos metais \\
\hline
\end{tabular}


Quadro 3: A condução térmica e a condução elétrica se aliam. (cont.)

\begin{tabular}{|c|c|c|c|}
\hline Turno & Locutor & Falas & $\begin{array}{l}\text { Ações do professor e dos alunos em relação à possível } \\
\text { emergência dos elementos do TAP }\end{array}$ \\
\hline 29 & Professor & $\begin{array}{l}\text { Pesquisem em seus celulares o que é uma ligação } \\
\text { metálica! (Ele se retira) }\end{array}$ & $\begin{array}{l}\text { Investe na retomada de conhecimentos teóricos - estrutura } \\
\text { dos metais }\end{array}$ \\
\hline 30 & & Alunos pesquisando (2 minutos) & \\
\hline 31 & Aluno 5 & Caracterizado por um subnível s e d incompletos... & Apresenta conhecimentos teóricos- estrutura dos metais. \\
\hline 33 & Aluno 5 & $\begin{array}{l}\text { A ligação metálica confere à substância um alto ponto de } \\
\text { fusão e vaporização... }\end{array}$ & Apresenta conhecimentos teóricos- estrutura dos metais. \\
\hline 34 & Professor & E aí pessoas, o que é um metal? & $\begin{array}{l}\text { Investe na retomada de conhecimentos teóricos - definição } \\
\text { de metal }\end{array}$ \\
\hline 35 & Aluno1 & Apresentam alta ductibilidade. & Apresenta conhecimento teórico -propriedade dos metais \\
\hline 38 & Professor & $\begin{array}{l}\text { Interessante! O que acontece se há um fluxo de calor } \\
\text { nestas condições? }\end{array}$ & $\begin{array}{l}\text { Busca estabelecer a relação entre fluxo de calor e fluxo } \\
\text { de elétrons. }\end{array}$ \\
\hline 39 & Aluno 1 & Ela começa a liberar todos os seus elétrons!! & Relaciona fluxo de calor a fluxo de elétrons \\
\hline 40 & Professor & $\begin{array}{l}\text { Então, como o fluxo de calor se alinha com os elétrons? } \\
\text { Do frio para o quente ou do quente pro frio? }\end{array}$ & $\begin{array}{l}\text { Busca estabelecer a relação entre fluxo de calor e fluxo } \\
\text { de elétrons. }\end{array}$ \\
\hline 41 & $\begin{array}{l}\text { Alunos (todos } \\
\text { juntos): }\end{array}$ & Do quente para frio... Hummmm.... & Relaciona fluxo de calor a fluxo de elétrons \\
\hline
\end{tabular}

Nesse episódio, as conclusões apresentadas pelos alunos (turnos 5, 17 e 18) como respostas às questões do professor não se constituíram em argumentos, de acordo com o Modelo de Argumento de Toulmin, à exceção do que ocorre no turno 3. Neste turno, os alunos do grupo investigado elaboram um argumento, todavia este não se refere a questões centrais relativas ao funcionamento da turbininha.

Isso se deve ao fato de que o principal objetivo do professor na interação foi investir no aprofundamento das características dos metais, da estrutura desse tipo de material, para que se avançasse na compreensão da relação entre o fluxo de calor e o fluxo de elétrons, ou seja, na compreensão de que a condução de eletricidade da placa à turbininha ocorre graças à diferença de temperatura entre as águas dos recipientes que se intercalavam com a placa. Tal conhecimento é importante para a compreensão do funcionamento da termoelétrica.

Desse modo, as ideias apresentadas pelos alunos às investidas do professor podem ser percebidas muito mais como voltadas a explicações do que a argumentos, de acordo com a diferenciação entre esses dois gêneros discursivos apresentada por Osborne e Patterson (2011). A delimitação entre explicação e argumentação não é algo simples e, até mesmo questionada, por alguns autores, como necessária, de modo a constituir-se como tema controverso. Portanto, embora no caso aqui discutido ela seja útil, não vamos nos deter nesse aspecto.
Osborne e Patterson (2011), sem o intuito de aprofundar em questões teóricas sobre como as explicações funcionam, observam que, quando se busca associar descrições, numa relação de causa e efeito entre elas, a fim de dar sentido a um fenômeno que se mostra como incontroverso (explanandum), tem-se apenas uma explicação. Quando se trata de construir um argumento, entretanto, há muito mais que uma característica ou comportamento a ser explicado, mas uma afirmação que precisa ser justificada, diante de outras que se mostram plausíveis.

Assim, quando os alunos elaboraram hipóteses para o que supunham que ocorreria no aparato experimental, considerando características deste aparato e outros dados empíricos, bem como conhecimentos teóricos que funcionavam como garantias de inferência, instaurou-se uma estrutura argumentativa. É relevante considerar que, na perspectiva do aluno, havia várias possibilidades de respostas às questões propostas pelo professor, as quais eles deveriam comparar entre si e ponderar qual seria mais viável do ponto de vista da ciência escolar. Isso ocorreu no episódio transcrito no Quadro 2. No episódio seguinte (transcrito no Quadro 3), todavia, o foco maior da discussão foi o entendimento sobre o que é uma ligação metálica, a fim de se avançar na compreensão da relação entre condução de corrente elétrica e térmica. $\mathrm{O}$ movimento discursivo se distancia de uma argumentação, aproximando de descrições e explicações, uma vez que não houve a necessidade de justificar um ponto 
de vista diante de um fenômeno que se buscava compreender, mas de se apropriar do um conhecimento já posto, que deveria ser incluído na discussão, sem ser problematizado.

É possível verificar ainda que, nesse $2^{\circ}$ episódio, os alunos avançam na compreensão da relação entre a condução térmica e a elétrica e isso se deve ao investimento do professor no sentido de direcionar suas ideias para a existência de uma nuvem de elétrons no metal. Isso pode ser percebido nos vários turnos em que o professor propõe problemas aos alunos e explora as ideias destes sobre conhecimentos teóricos e dados experimentais. São 17 turnos em que o professor investe nesses aspectos até que os alunos conseguem dar início à percepção da relação entre o fluxo de energia e o fluxo de elétrons.

Os turnos 37 e 39 explicitam concepções que se aproximam da ideia de que o fluxo de calor será responsável por uma maior movimentação dos elétrons da placa e que tal movimentação se estende ao longo dos fios, de modo a proporcionar a passagem constante da corrente elétrica pela turbininha. Todavia, tais ideias precisam ainda ser ajustadas às concepções cientificamente corretas. No turno 39, por exemplo, A1 declara que "Ela (a placa) começa a liberar todos os seus elétrons".

Neste contexto, as interpretações espontâneas acerca do fenômeno estudado são importantes para se desenvolver pensamentos mais elaborados. Para tal, os alunos devem compreender o sistema termodinâmico em análise, considerando seus princípios teóricos e sua estrutura, de modo a perceber os locais de entrada e saída de energia. Esta afirmação está de acordo com Silva (2009), quando considera que os alunos não compreendem facilmente a ideia de sistema termodinâmico.

Prevaleceu aí também uma abordagem interativa/de autoridade por parte do professor. Conclui-se que sem a intervenção do professor no processo, os alunos certamente não articulariam os conhecimentos teóricos da Física e da Química na experimentação do Gerador Termoelétrico. A termodinâmica trabalha, em sua essência, com várias modalidades de energia. Todavia, a abordagem tradicionalmente adotada nas escolas se dá de forma a fragmentá-las nos currículos da Química e da Física. Em nossa SEI, houve um aumento de complexidade no experimento posto em discussão, visto que se buscou associar energia em trânsito (calor) à movimento elétrico.

Após estas discussões, os alunos foram solicitados a responder, por escrito, às perguntas descritas na metodologia. Portanto, as respostas a tais questões constituem-se em argumentos que estruturamos segundo o Modelo de Toulmin, conforme as figuras de números 4 a 7. Os esquemas elaborados resultam da análise dos argumentos de todos os alunos da turma (25) expressos por escrito, de forma individual.

Na discussão que segue, apresentamos, para cada questão proposta no roteiro da atividade, um exemplo de argumento elaborado como resposta a tal questão, além do percentual que representa a frequência desse tipo de argumento em relação ao total de respostas.

É relevante verificar que estes argumentos escritos, produzidos após a análise do experimento e discussão do professor com cada grupo em particular e com toda a turma, são mais bem elaborados, tanto estrutural, quanto conceitualmente, que aqueles produzidos no início da atividade. Isso evidencia o avanço conceitual dos alunos, bem como sua capacidade de argumentação.

$\mathrm{Na}$ Figura 5, temos o argumento relacionado à primeira questão (Problema 1) - "Qual a principal variável para o sistema funcionar? Como você concluiu isso?" Vejamos a resposta do Aluno 7:

"Variação de calor. Observando o experimento,
em um pote foi colocado um líquido gelado e em
outro um liquido quente e isso é passado pela placa
que fica entre os potes metálicos. O metal é um ótimo
condutor de calor, de energia elétrica. A produção
é ocorrida pela agitação dos elétrons presentes no
metal." (Aluno 7)

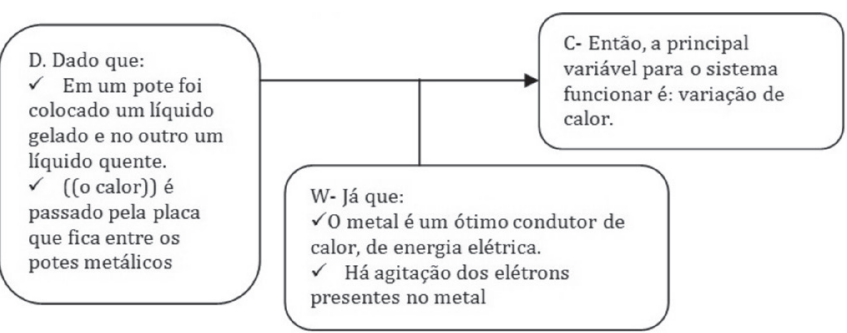

Figura 5: Esquema de Toulmin para a resposta à questão: Qual a principal variável para o sistema funcionar? Como você concluiu isso?

Nesse momento, após as discussões dos experimentos, a maioria dos alunos, a exemplo do Aluno 7, demonstra entender que a passagem de energia ocorre do quente para o frio e que a diferença de temperatura resulta na geração de energia elétrica. Isso é importante para que se perceba que as termoelétricas precisam receber calor de uma fonte à alta temperatura e descarregá-lo em outra fonte à baixa temperatura. A diferença de temperatura indica que o trabalho elétrico foi conseguido através do fluxo de energia promovido por um $\Delta \mathrm{t}$.

Desta forma, $86,7 \%$ dos alunos de toda a turma percebem a interligação entre a condução térmica e a condução elétrica através da placa de Peltier, adequadamente, confirmando também a necessidade da existência de dois sistemas com temperaturas distintas para que ocorra o fenômeno de energia em trânsito na forma de calor. Por outro lado, $13,3 \%$ dos alunos não desenvolveram um argumento que tecia relações entre os dados experimentais e aspectos teóricos fornecidos ou fomentados pelo professor. O próprio Aluno 7 refere-se à variação de calor, ao invés de variação de temperatura. Decerto que a energia na forma de calor varia em função do gradiente de temperatura entre as águas, mas é esta última que corresponde a variável independente, manipulada no experimento.

O Aluno 13, por sua vez, refere-se ao calor considerando "troca de calor", a qual gera energia (elétrica), vejamos: 
A energia gerada pela troca de calor entre as duas latinhas. Eu conclui isso observando o sistema. Pois a energia só foi gerada quando o fluido quente entrou em contato com o fluido frio e o motor começou a girar. O metal tem elétrons livres e quando é aquecido há uma agitação das moléculas e o deslocamento dos elétrons gerando energia. (Aluno 13)

Outros alunos, a exemplo do Aluno 9, incluso também nos $86,7 \%$, refere-se à variação de temperatura, como expresso abaixo:

"A variação de temperatura. A passagem de energia térmica da água quente para a água fria provoca energia cinética na placa através de sua capacidade de condutividade elétrica que movimenta o motor e há liberação de elétrons da última camada que passa pelos fios, por não ter outro caminho". (Aluno 9)

Uma diferença que aparentemente é sutil, porém, revela a fidedignidade quanto aos dados experimentais e não uma extrapolação.

Na Figura 6, apresentamos mais uma descrição do Modelo de Toulmin, agora para as respostas à questão 2 (O que faço para ter uma maior geração de eletricidade?).

Vejamos a resposta do aluno 22:

Com o aumento de $\Delta T$ entre os dois fluidos, pois quanto maior for a troca de calor entre eles maior será a energia gerada, pois a condutibilidade térmica se transforma em energia elétrica. (Aluno 22)

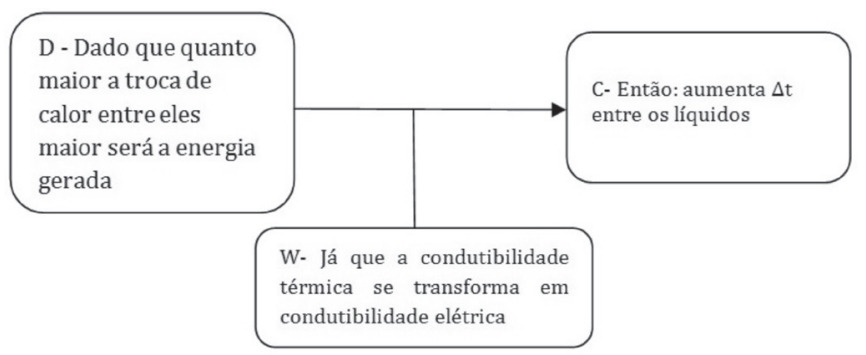

Figura 6: Esquema de Toulmin para a resposta à questão: O que faço para ter uma maior geração de eletricidade?

$\mathrm{O}$ argumento apresentado faz parte dos $80 \%$ que representam os alunos que reorganizam suas ideias também considerando os conceitos básicos da condução de energia na forma de calor. Porém, associar a condução térmica à condução elétrica num condutor necessita de um período maior de interação com o professor, como pode ser percebido no que nos mostram os Quadros 1 e 2 desta sessão. Deste modo, 20\% dos alunos não alcançaram os argumentos esperados.

A Figura 7 expressa os argumentos dos alunos como resposta à Questão 3 (A energia, na forma de calor, é totalmente aproveitada no aparelho para gerar eletricidade?), os quais baseiam-se na Segunda Lei da Termodinâmica $(93,3 \%)$, a qual aparece nos textos, explícita ou implicitamente. Entretanto, 6,7\% não apresentaram um argumento compatível com as definições conceituais envolvidas nesta lei. Cabe ressaltar que, muitos desses argumentos que relacionam o fenômeno à segunda Lei da termodinâmica carecem de refinamento teórico; todavia, podem ser considerados como um avanço ne aprendizagem, alcançado por meio do processo interativo argumentativo conduzido pelo professor.

Vejamos a resposta do Aluno 19:

Não, porque na $2^{a}$ Lei da Termodinâmica o calor não é $100 \%$ transformado em trabalho em um sistema aberto. Há transferência de calor tanto para o meio externo quanto para o outro fluido, podemos perceber isso pois isso se passa num sistema aberto. (Aluno 19)

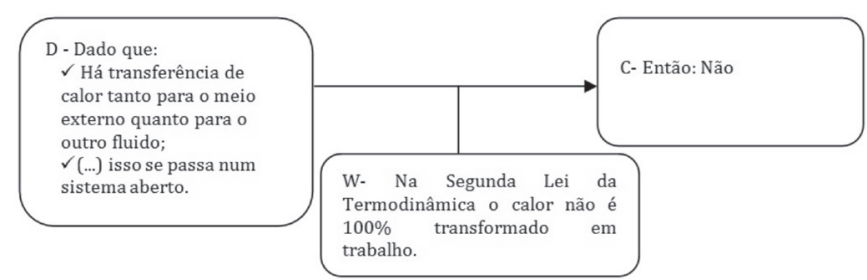

Figura 7: Esquema de Toulmin para a resposta à questão: A energia na forma de calor para gerar eletricidade é totalmente aproveitada no aparelho?

Conforme informamos, de diferentes formas os alunos referem-se aos princípios de conservação da energia, da $2^{\mathrm{a}}$ Lei da Termodinâmica e de suas relações com sistemas abertos que ocorrem à pressão constante. Outros trazem informações referentes a conhecimentos oriundos de suas experiências além das aulas dessa sequência. Vejamos:

Não. Se os mais adaptados meios de energia não conseguem o aproveitamento total, imaginem esse experimento simples e cheio de falhas. Não existe fonte de energia totalmente aproveitável, pois sempre há perda de energia para o ambiente. (Aluno 10)

A Figura 8 expressa os argumentos que constituem as respostas dos alunos à Questão 4 ("O que acontece quando um fluxo de energia na forma de calor atravessa um metal? O que será gerado?"). Nesse sentido, torna-se fundamental considerar a estrutura dos metais compreendendo em que consiste uma ligação metálica. O esquema representa uma síntese das respostas escritas pelos alunos no grupo tomado para análise, após a intervenção do professor.

Vejamos a resposta do grupo:

O metal tem elétrons livres. Os elétrons serão alinhados pelo fluxo de calor, pois, o fluxo de calor anda junto com o fluxo de elétrons. 


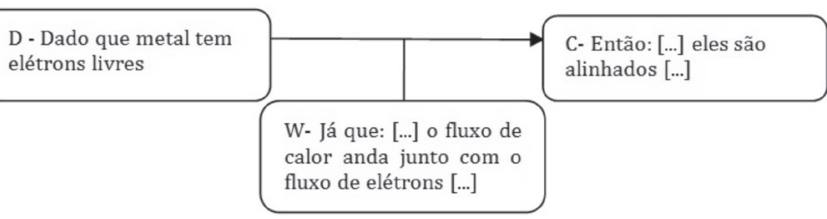

Figura 8: Esquema de Toulmin para a resposta à questão: Como é a ligação em metais? O que acontece quando um fluxo de energia na forma de calor é atravessado em sua extensão? O que será gerado?

De acordo com os alunos, há um aumento de energia cinética nos elétrons, uma vez que a diferença de temperatura possibilita a transferência de energia térmica e assim, gera a corrente elétrica.

É importante ressaltar a ausência da expressão "a menos que", um elemento de contestação (refutador), em todos os argumentos. Uma das possibilidades para isso é a de que os conhecimentos que compõem as garantias de inferência nos argumentos correspondentes às respostas dos alunos são princípios fundamentais da termodinâmica, os quais não apresentam exceções. Nessa mesma perspectiva há, ainda, conhecimentos relativos à estrutura dos metais.

Certamente, os alunos poderiam explorar mais, em seus argumentos, a relação entre as condições reais do experimento e as condições ideais consideradas nas leis e teorias da ciência, de modo a gerar refutadores compondo uma discussão mais aprofundada em resposta às questões propostas. Todavia, isso não apenas requereria maior habilidade argumentativa dos alunos, como também um maior conhecimento do conteúdo. Consideramos que os alunos não estavam habituados à prática da argumentação na perspectiva da ciência, de modo a ponderar em que condições conclusões elaboradas a partir de dados experimentais podem ser consideradas válidas ou não. Isso deve ser explorado ao longo da escolarização do aluno. Como discutido por Garcia-Milla et al. (2013), refutadores conferem mais qualidade aos argumentos por evidenciar a percepção das limitações das conclusões e se adiantar a possíveis contra-argumentos.

\section{Considerações Finais}

Os resultados deste artigo evidenciam o processo de elaboração conjunta de argumentos pelos alunos em função das intervenções do professor ao longo da análise do experimento proposto. Neste percurso, ideias anteriores foram retomadas e outras novas, sobretudo a relação entre a condução de energia na forma de calor e de eletricidade, foram construídas. A articulação entre os conhecimentos teóricos, o aparato experimental e os resultados empíricos resultaram em um avanço conceitual acerca das interligações entre os conceitos de calor, condução elétrica e ligação metálica.

$\mathrm{O}$ investimento do professor em promover o compartilhamento e internalização de conhecimentos teóricos pelos alunos, de modo que eles pudessem dar sentido aos dados experimentais investigados resultou em argumentos mais elaborados estrutural e conceitualmente, os quais se expressaram nas respostas escritas às questões propostas no roteiro da atividade experimental. Desta forma, os elementos constituintes do Modelo de Argumento de Toulmin surgiram, ao longo das interações, de modo incompleto até constituírem gradativamente em argumentos mais estruturados nos textos escritos. Mostra-se, assim, o papel de mediador e de autoridade do professor no favorecimento da passagem de argumentos frágeis a argumentos estrutural e conceitualmente consistentes.

Todavia, é importante considerar que os argumentos construídos apresentaram apenas a estrutura básica proposta por Toulmin. Entendemos que a habilidade dos alunos em elaborar argumentos mais sofisticados é algo que demanda um investimento maior de tempo, tanto nas interações aluno-aluno e professor-aluno, quanto na escrita de seus pontos de vista em função das solicitações do professor nessa direção, ao longo da escolarização. Nessa perspectiva, estruturas mais sofisticadas de argumentos, com a presença de qualificadores e refutadores por exemplo, não apareceram nos textos dos alunos, os quais não tinham familiaridade com o estilo de aula desenvolvida e as demandas argumentativas requeridas.

Apesar de haver um investimento crescente na pesquisa em argumentação nos últimos 25 anos (Jiménez-Aleixandre et al., 1999; Erduran e Jiménez-Aleixandre, 2011; Erduran e JimenezAleixandre, 2012), a habilidade para desenvolver argumentos não é um objetivo usualmente perseguido nas salas de aula de ciências no Brasil.

O que expressa a elaboração de argumentos científicos consistentes nos textos dos alunos desta pesquisa é a articulação adequada entre dados experimentais, garantias de inferência e conclusões. A argumentação científica presume alegações ancoradas em evidências por meio de constructos teóricos que garantam as inferências elaboradas. Um maior avanço nesse sentido presume um investimento contínuo em atividades investigativas que fomentem, por meio de estratégias frutíferas, a habilidade de argumentar dos alunos, como vem sendo requerido em distintas propostas curriculares em diferentes partes do mundo (Garcia-Mila et al., 2013).

Do ponto de vista metodológico, optamos, em nossa pesquisa, por considerar tanto as interações entre os alunos do grupo investigado na elaboração conjunta de argumentos, quanto a produção de textos escritos individualmente. Entendemos que, dessa forma, é possível verificar como as ideias iniciais dos alunos começam a se articular no plano social da sala de aula e, posteriormente, evoluem e são internalizadas. Ponderamos que essa articulação entre o processo argumentativo e os argumentos gerados, em uma perspectiva analítica e pedagógica sociocultural, merece ser mais explorada na pesquisa em Educação em Ciências.

Por fim, outro aspecto que deve ser ressaltado neste trabalho, é a articulação entre as disciplinas Química e Física com a finalidade de interligar conceitos e abordar aspectos tecnológicos, tendo em vista o funcionamento de uma termoelétrica. Nesse 
sentido, os leitores desta revista podem aplicar este experimento em sala de aula, com um olhar mais voltado às investidas do professor no sentido de conduzir as concepções dos alunos àquelas cientificamente corretas, aliadas a uma boa estrutura de texto argumentativo.

\section{Nota}

${ }^{1}$ De acordo com Mortimer e Scott (2003), a abordagem comunicativa caracteriza o discurso adotado pelo professor em direção aos alunos, indicando o modo como ele trabalha as suas intenções e o conteúdo de ensino, tendo como resultado diferentes padrões de interação. Os autores propõem quatro classes de abordagem comunicativa, em termos de duas dimensões: discurso "dialógico - de autoridade" e discurso "interativo - não interativo". Sendo assim, tem-se as seguintes classes de abordagem comunicativa: Interativa/Dialógica, Interativa/ De autoridade, Não-Interativa/Dialógica e Não-Interativa/De autoridade. Na abordagem de Interativa/De autoridade, o professor alterna turnos de fala com os alunos e interessa-se pelo ponto de vista da ciência escolar, de modo a buscar convergir as ideias dos alunos àquelas cientificamente aceitas.

\section{Agradecimentos}

Agradecemos ao professor, que abiu as portas de sua sala de aula para a pesquisa, e à Capes, pelo apoio financeiro.

\section{Referências}

BRAATHEN, P. C.; LUSTOSA, A. A.; FONTES, A. C. e SEVERINO, K. G. Entalpia de decomposição do peróxido de hidrogênio: uma experiência simples de calorimetria com material de baixo custo e fácil aquisição. Química Nova na Escola, v. 29, p. 42 - 45, 2008.

CALlister, W. D., Ciência e Engenharia de Materiais: Uma Introdução. John Wiley \& Sons, Inc., 2002.

CAPECCHI, M. C. V. M. e CARVALHO, A. M. P. Argumentação em uma aula de conhecimento físico com crianças na faixa de oito a dez anos. Investigações em Ensino de Ciências, v. 5, n. 2, p. 171-189, 2000.

CARMO, A. B. e CARVALHO, A. M. P. Uma proposta de sequência de ensino investigativa sobre quantidade de movimento, sua conservação e as leis de Newton. Caderno Brasileiro de Ensino de Física, v. 31, p. 30-59, 2014.

CARRASCOSA, J.; GIL-PÉREZ, D.; VILCHES, A. E.e VALDÉS, P. Papel de la actividad experimental en la educación científica. Caderno Brasileiro de Ensino de Física, v. 23, n.2, p. 157-181, 2006.

DUSCHL, R. Quality argumentation and epistemic criteria. In: ERDURAN, S.; JIMÉNEZ-ALEIXANDRE, M. P. (Ed.). Argumentation in science education: perspectives from classroombased research. Dordrecht: Springer, p.159-178, 2008

EEMEREN, F. H. van; GROOTENDORST, R.; HENKEMANS, F. S.; BLAIR, J. A.; JOHNSON, R. H.; KRABBE, E.C.W.; PLANTIN, C.; WALTON, D. N.; WILLARD, C. A.; WOODS, J e ZAREFSKY,
D. Fundamentals of argumentation theory: A handbook of historical backgrounds and contemporary developments. Mahwah, N.J.: Lawrence Erlbaum, 1996.

ERDURAN, S. Methodological foundations in study of argumentation in science classrooms. In: ERDURAN. S.; JIMÉNEZ-ALEIXANDRE, M. P. (Ed.). Argumentation in science education: perspectives from classroom-based research. Dordrecht: Springer, 2007. p. 47-70.

Methodological foundations in the study of argumentation in science classrooms. In: ERDURAN, S.; JIMÉNEZ-ALEIXANDRE, M. P. (Eds.). Argumentation in science education: perspectives from classroom-based research. Dordrecht: Springer, 2008, p. 47-69.

ERDURAN, S.e JIMÉNEZ-ALEIXANDRE, M. P. Argumentation in science education: perspectives from classroom - based research. Science \& Education, v. 20, n. 5, p. 585-588, 2011.

Research on argumentation in science education in Europe. In. D. Jorde, \& J. Dillon (Eds), Science Education Research and Pratice in Europe: Restrospective and Prospective. Rotterdam: Science Publishers, 2012 p. 253-289.

ERDURAN, S.; SIMON, S.e OSBORNE, J. TAPping into argumentation: developments in the application of Toulmin's argument pattern for studying science discourse. Science Education, Hoboken, v. 88, n. 6, p. 915-933, 2004.

FERRAZ, A. T.e SASSERON, L. H. Espaço interativo de argumentação colaborativa: condições criadas pelo professor para promover argumentação em aulas investigativas, Ensaio: Pesquisa em Educação em Ciências, v. 19, p. 1- 25, 2017a.

FERRAZ, A. T.e SASSERON, L.H.; Propósitos epistêmicos para a promoção da argumentação em aulas investigativas. Investigações em Ensino de Ciências, v. 22, n. 1, p. 42-60, 2017b.

GARCIA-MILLA, M.; GILABERT, S.; ERDURAN, S.e FELT, M. The effect of argumentative task goal on the quality of argumentative discourse. Science Education, v. 97, n. 4, p. 497-523, 2013.

HODSON, D. Hacia un enfoque más crítico del trabajo del laboratorio. Enseñanza de las Ciencias, 12 (3): 299 - 313. 1994.

. Learning science, learning about science, doing science: different goals demand different learning methods. International Journal of Science Education, v. 36, n. 15, p. 2534-2553, 2014.

JIMÉNEZ-ALEIXANDRE, M.P.; REIGOTA, C.C.e ÁLVAREZ-PÉREZ, V. Argumentación en el laboratório de Física. Atas do V Encontro de Pesquisa em Ensino de Física, 1998.

JÍMENEZ-ALEIXANDRE, M.P.; RODRIGUES, A.B.e DUSCHL, R.A. "Doing the lesson" or "doing science": argument in high school genetics. Science Education, v. 84, n. s/n, p. 757-792, 2000.

KELLY, G. J. Inquiry, activity, and epistemic practice. Paper apresentado na Inquiry Conference on Developing a Consensus Research Agenda. New Brunswick, NJ. fev. 2005.

KUHN, D. The skills of argument. Cambridge: Cambridge University Press, 1991, 324p.

LEMKE, J. L. Talking science: language, learning and values. New Jersey: Ablex Publishing Corporation, 1990.

MORAES, T. S. V.e CARVALHO, A. M. P. Proposta de sequência de ensino investigativa para o $1^{\circ}$ ano do ensino fundamental, Espaço Pedagógico, v. 25, p. 407-437, 2018. 
MORTIMER, E. F. Evolução do atomismo em sala de aula; mudança de perfis conceituais. Tese de Doutorado (Doutorado em Educação). Universidade de São Paulo, São Paulo, 1994.

Multivoicineness and univocality in classroom discourse: an example from theory of matter. International Journal of Science Education, 20(1): 67-82, 1998.

MORTIMER, E. F.e MACHADO, A. H. Anomalies and Conflicts in Classroom Discourse. Science Education, v.84, p.429 - 444, 2000.

. Meaning making in secondary science classrooms. Buckingham: Open University Press, 2003.

NASCIMENTO, S. S e VIEIRA, R. D. A argumentação em sala de aula de física: limites e possibilidades de aplicação do padrão de Toulmin. In: NASCIMENTO, S. S; PLANTIN, C. (Org.). Argumentação $e$ ensino de Ciências. 1ed. Curitiba: CRV, v. 1, p. 17-37, 2009.

OSBORNE, J. e PATTERSON, A. Scientific argument and explanation: a necessary distinction? Science Education, v. 95, p. 627-638, 2011.

PEDASTE, M., MÄEOTS, M., SIIMAN, L., JONG, T., RIESEN, S., KAMP, E., MANOLI, C., ZACHARIA, Z. e TSOURLIDAKI, E. Phases of inquiry-based learning: definitions and the inquiry cycle. Educational Research Review, v. 14, p. 47-61, 2015.

RATZ, S.V.S. e MOTOKANE, M.T. A construção dos dados de argumentos em uma sequência didática investigativa em ecologia. Ciência \& Educação, v. 22, n. 4, p. 951-973, 2016.

SÁ, L.P.; KASSEBOEHMER, A.C. e QUEIROZ, S.L. Esquema de argumento de Toulmin como instrumento de ensino: explorando possibilidades. Revista Ensaio, v. 16, n. 3, p. 147-170, 2014.
SANDOVAL, W. Understandings students' pratical epistemologies and their influence on learning through inquiry. Science Education, v. 89, p. 634-656, 2005.

SANTOS, W.L.P. Contextualização no ensino de ciências por meio de temas CTS em uma perspectiva crítica. Ciência \& Ensino, v. 1, n. especial, p. 1-12, 2007.

SASSERON, L.H. Alfabetização científica no ensino fundamental: estruturas e indicadores deste processo em sala de aula. Tese de Doutorado (Doutorado em Ensino de Ciências) Universidade de São Paulo, São Paulo, 2008.

SCOTT, P. H. Teacher talk and meaning making in science classrooms: a vygotskian analysis and review. Studies in Science Education, v. 32, p. 45-80, 1998.

SILVA, D. N. A termodinâmica no ensino médio: ênfase nos processos irreversíveis, dissertação de mestrado (Mestrado em Ensino de Ciências), Universidade de São Paulo, São Paulo, 2009.

TOULMIN, S. E. Os usos do argumento. São Paulo: Martins Fontes, 2. Ed., 2006.

VIEIRA, A. T. A dimensão avaliativa da argumentação na fala opinativa de profissionais de uma empresa em processo de mudança. Tese (Doutorado em Letras) - Pontifícia Universidade Católica do Rio de Janeiro, Rio de Janeiro, 2007.

VYGOTSKY, L. S. Pensamento e linguagem. São Paulo: Martins Fontes, 1993.

ZOHAR, A.; NEMET, F. Fostering students' knowledge and argumentation skills through dilemmas in human genetics. Journal of Research in Science teaching, v. 39, n. 1, p. 35-62, 2002. 